\title{
RESEARCH
}

Open Access

\section{Myositis ossificans traumatica of the masticatory muscles: etiology, diagnosis and treatment}

Marcel Hanisch ${ }^{1 *}$ (D, Lale Hanisch², Leopold F. Fröhlich ${ }^{3}$, Richard Werkmeister ${ }^{4}$, Lauren Bohner ${ }^{1}$ and Johannes Kleinheinz'

\begin{abstract}
Background: Myositis ossificans describes a heterotopic bone formation within a muscle. Thereby myositis ossificans is classified in two different groups: myositis ossificans progressiva (MOP) which describes a genetic autosomal dominant rare disease and myositis ossificans traumatica (MOT). The exact pathogenesis of MOT is unclear. The aim of this article was to analyse and interpret the existing literature reporting MOT of masticatory muscles and compare the results with our own clinical experience with MOT. Risk-factors, etiology, clinical features, diagnostic imaging, as well as different treatment options were evaluated and recommendations for the prevention, diagnosis, and therapy of MOT of the masticatory muscles were given.

Methods: Following the PRISMA-Guidelines, a systematic search within the PubMed/Medline database with a view to record literature of MOT of the masticatory muscles was performed. Furthermore, the database of our own clinic was screened for cases of MOT.

Results: In total, 63 cases of MOT of the masticatory muscles which were reported in English-based literature were included in this study. Overall, 25 female and 37 male patients could be analysed whereas one patient's gender was unknown. Complication of wisdom-tooth infection $(n=3)$ as well as the results of dental procedures like dental extraction $(n=7)$, mandibular nerve block $(n=4)$, periodontitis therapy $(n=1)$ were reported as MOT cases. From the 15 reported cases that appeared after dental treatment like extraction or local anesthesia the medial pterygoid $(n=10)$ was the most affected muscle. Hereof, females were more affected $(n=9)$ than males $(n=6)$. The most reported clinical symptom of MOT was trismus $(n=54)$, followed by swelling $(n=17)$ and pain $(n=13)$. One clinical case provided by the authors was detected.

Conclusions: Dental procedures, such as local anesthesia or extractions, may cause MOT of the masticatory musculature. Demographical analyses demonstrate that females have a higher risk of developing MOT with respect to dental treatment. The most important treatment option is surgical excision. Subsequent physical therapy can have beneficial effects. Nevertheless, a benefit of interpositional materials and drugs as therapy of MOT of the masticatory muscles has not yet been proven. Myositis ossificans progressiva has to be excluded.
\end{abstract}

Keywords: Myositis ossificans, Myositis ossificans traumatica, Myositis ossificans circumscripta, Heterotropic ossification, Masticatory muscles

\footnotetext{
* Correspondence: marcel.hanisch@ukmuenster.de

'Department of Cranio-Maxillofacial Surgery, Research Unit Rare Diseases with Orofacial Manifestations (RDOM), University Hospital Münster, Albert-Schweitzer-Campus 1, Gebäude W 30, D-48149 Münster, Germany Full list of author information is available at the end of the article
}

(c) The Author(s). 2018 Open Access This article is distributed under the terms of the Creative Commons Attribution 4.0 International License (http://creativecommons.org/licenses/by/4.0/), which permits unrestricted use, distribution, and reproduction in any medium, provided you give appropriate credit to the original author(s) and the source, provide a link to the Creative Commons license, and indicate if changes were made. The Creative Commons Public Domain Dedication waiver (http://creativecommons.org/publicdomain/zero/1.0/) applies to the data made available in this article, unless otherwise stated. 


\section{Background}

Myositis ossificans describes a heterotopic bone formation within a muscle. Depending on its cause, the syndrome was classified into two different groups: myositis ossificans progressiva (MOP), also known as fibrodyplasia ossificans progressiva which describes a genetic autosomal dominant genetic disease, and myositis ossificans traumatica (MOT). According to its name MOP develops systemically in muscles, ligaments, fascia, and tendons [1]. The prognosis for MOP is generally poor $[2,3]$. However, MOT, which is also called myositis ossificans circumscripta, is characterized by ectopic bone formation within muscles and other soft tissues as a result of a preceded trauma [4]. Recent literature also defines further types of myositis ossificans like post-infectous myositis ossificans [5] or idiopathic myositis ossificans [6]. MOT is mostly reported in the orthopedic literature as a result of repeated trauma in muscles like quadriceps femoris. In masticatory muscles, however, MOT is a rare condition which was first reported by Ivy and Eby in 1924 affecting the masseter muscle [7]. In this sense, trismus is the most frequent symptom in the masticatory muscles [8]. The diagnosis MOT can be made if trauma, characteristic clinical and radiological signs, as well as histopathological confirmation are presented [9]. Differential diagnosis must be performed to exclude malignancies like sarcomas, or chondrosarcomas, as well as other neoplasias like osteoma, haemangioma, osteochondroma, or nodular fascitis [10]. Also the anchored disc phenomen and myofibrotic contracture of muscle should be considered [1]. The exact mechanism of the pathogenesis of MOT is unclear. Nevertheless, traumatic, iatrogenic lessions caused by the dentist such as extractions, mandibular block, or periodontal therapy are suspected to be a triggering factor similary to infections like pericoronitis $[2,5,10-21]$. Therefore, the aim of this article was to analyse and interpret the existing literature reporting MOT of masticatory muscles and compare the results with the authors own clinical experience with MOT. The focused question to be answered in this review was: what etiological factors, clinical symptoms, diagnostic imaging and treatments options are reported in current literature to the prevention, diagnosis and therapy of MOT of the masticatory muscles?

\section{Methods}

\section{Literature review}

Protocol

The literature search was conducted in accordance to the guidelines available at the "Preferred Reporting Items for Systematic Reviews and Meta-Analyses" (PRISMA) [22].

\section{Eligibity criteria}

The inclusion criteria consisted of studies describing clinical data reporting on myositis ossificans of the masticatory muscles since the year of the first report (1924) up to date. Due to the lack of clinical trials regarding this issue, no restriction was applied to the study design. Conversely, literature review, books or abstracts or those written in other language than english were excluded from this study.

\section{Search strategy}

A search strategy was constructed based on PICOS $(\mathrm{P}=$ patients; $\mathrm{I}=$ Intervention; $\mathrm{C}=$ Comparison; $\mathrm{O}=$ Out come, $\mathrm{S}=$ Study design), as described in Table 1 . The search was conducted in PubMed/Medline database from July to October 2016. Additionally, a manual search was performed based on the references of the screened articles.

\section{Study selection}

The study selection was independently performed by two reviewers ( $\mathrm{MH}$ and $\mathrm{LH}$ ) and, in case of disagreement, a third reviewer (JK) was consulted. First, the articles were screened based on the review of titles and abstracts. Thus, the screened articles were selected for full-text reading and only those considered relevant for this review were included for analysis.

\section{Data collection process and items}

The first reviewer $(\mathrm{MH})$ extracted the relevant data from the eligible articles and organized them in tables, which were then crosschecked by the second reviewer (LH). The extracted data comprised information regarding gender and age of the affected patient, chief-compliant,

Table 1 Search strategy constructed based on PICOS

\begin{tabular}{ll}
\hline ICOS & Search terms \\
\hline $\mathrm{P}=$ Patients with MOT & - "myositis ossificans traumatica \\
$\mathrm{I}=$ Ossification of masticatory muscles & - "mD masticatory muscle" \\
$\mathrm{C}=-$ & AND masseter" \\
$\mathrm{O}=$ Diagnosis, prevention and treatment & - "myositis ossificans traumatica \\
$\mathrm{S}=$ clinical studies, case reports & - "mD pterygoid" \\
& AND temporalis ossificans traumatica \\
& - "myositis ossificans circumscripta \\
& AND masticatory muscle" \\
- "myositis ossificans circumscripta & AND masseter" \\
- "myositis ossificans circumscripta & AND pterygoid" \\
- "myositis ossificans circumscripta & AND temporalis" \\
- "fibrodysplasia ossificans circumscripta & AND masticatory muscle" \\
- "fibrodysplasia ossificans circumscripta & AND masseter" \\
- "fibrodysplasia ossificans circumscripta & AND pterygoid" \\
- "fibrodysplasia ossificans circumscripta & AND temporalis" \\
\hline
\end{tabular}


affected muscle, history of trauma, treatment protocol, surgical intervention, and follow-up assessment.

\section{Risk of bias within studies}

The qualitative assessment of the studies was performed using a critical appraisal checklist for case reports [23]. The original check-list consisted of 8 items assessing the quality of case reports. For this study, one item of the original check-list was excluded ("Were adverse events or unanticipated events identified and described?"), as this was not applicable for the most part of the selected studies. All items were marked as yes, no, or unclear. Further, the percentage of positive response (yes) was calculated for each study (Additional file 1).

\section{Clinical case reported by the authors}

The ethical approval for this study was obtained from the ethical review committee (Ref. no. 2017-052-f-N), Ethikkommission der Ärztekammer Westfalen-Lippe und der Westfälischen Wilhelms-Universität, Münster, Germany.

The electronic documentation system, which was maintained in our Dental-Clinic (University Hospital Münster) since 2010, was screened for cases of MOT. The following (german) search terms were used:

- Myositis ossificans

- MOT

- Heterotrope Ossifikation

- Fibrodyplasia ossificans

\section{Results}

\section{Literature review}

\section{Study selection}

A first literature search in PubMed database with the keywords indicated in Methods displayed 97 entries. After removing duplicates, 46 articles remained which underwent preselection by screening their abstracts. During the preselection round, two articles were excluded since they were not published in English language (Italian, Turkish) and further 12 articles were eliminated since they did not describe MOT. From these 12 excluded reports, 11 represented MOP cases and one reported about the Carey-Fineman-Ziter syndrome. Subsequently, 32 full-length articles were selected of which one was further excluded because of not detailing MOT. Screening of the references from these selected 31 articles led to further inclusion of 38 articles from which four were rejected again due to publication in national language (German: 2, Japanese: 1, Russian: 1), not describing MOT $(n=4)$, or unavailability $(n=2)$. The mode of literature search was summarized in Fig. 1.

As a final result, it was possible to provide 59 articles reporting about 63 cases of MOT of the masticatory muscles in this study. The study characteristics of the included articles are described in Table 2.

\section{Results of individual studies \\ Gender prevalence and age}

Overall, 63 patients were reported involving 25 female and 37 male patients that were analysed. One patient's gender was not indicated. Therefore, approximately two out of three patients were male. The age ranged from 10 to 73 years in the female group (mean: 38.6 years). In the male group the age ranged from 21 to 68 years (mean: 37.4 years).

\section{Affected muscle}

The most frequent affected muscle was the masseter muscle, which was hit 35 times (left side: 23-fold, right side: 11-fold, side unknown: 1-fold). The temporalis muscle was concerned 22 times (left side: 14-fold, right side: 8 -fold) followed by the medial pterygoid muscle with 21 cases (left side: 12-fold, right side: 9-fold). The lateral pterygoid muscle was affected 12 times (left side: 8 -fold, right side: 4 ). In18 cases more than a single muscle was hit by MOT.

\section{Clinical symptoms}

The most reported clinical symptoms of MOT were trismus $(n=54)$, followed by swelling $(n=17)$, and pain $(n$ $=13$ ). Facial paralysis was outlined in one case, while three cases were reported to be devoid of any clinical symptoms. Trismus ranged from 0 to $15 \mathrm{~mm}$ (mean: $7.3 \mathrm{~mm})$.

\section{Kind of trauma}

As triggering event, strokes or falls were reported most frequently $(n=21)$, while in 12 cases a triggering event was unknown. Car accidents seemed to be the reason for five cases of MOT but MOT development due to dental procedures like dental extraction $(n=7)$, mandibular nerve block $(n=4)$, periodontitis therapy $(n=1)$, or as a result of alcohol injection into the alveolar nerve $(\mathrm{n}=2)$ were also described. MOT as a complication of wisdom-tooth infection was reported in three cases. Furthermore, occurrence of MOT was published as a consequence of post-fracture $(n=3)$, gunshot injury $(n=2)$, perforating wound $(n=1)$, injury caused by a shell $(n=$ $1)$, and after intubating a patient for 4 weeks $(n=1)$.

\section{Time interval from trauma to treatment}

Time intervals from trauma to treatment were not addressed in 13 cases, while in two reports no treatment was initiated. In 48 cases, time intervals were reported, which ranged from 3 weeks to 25 years, whith an average time of 31 months. 


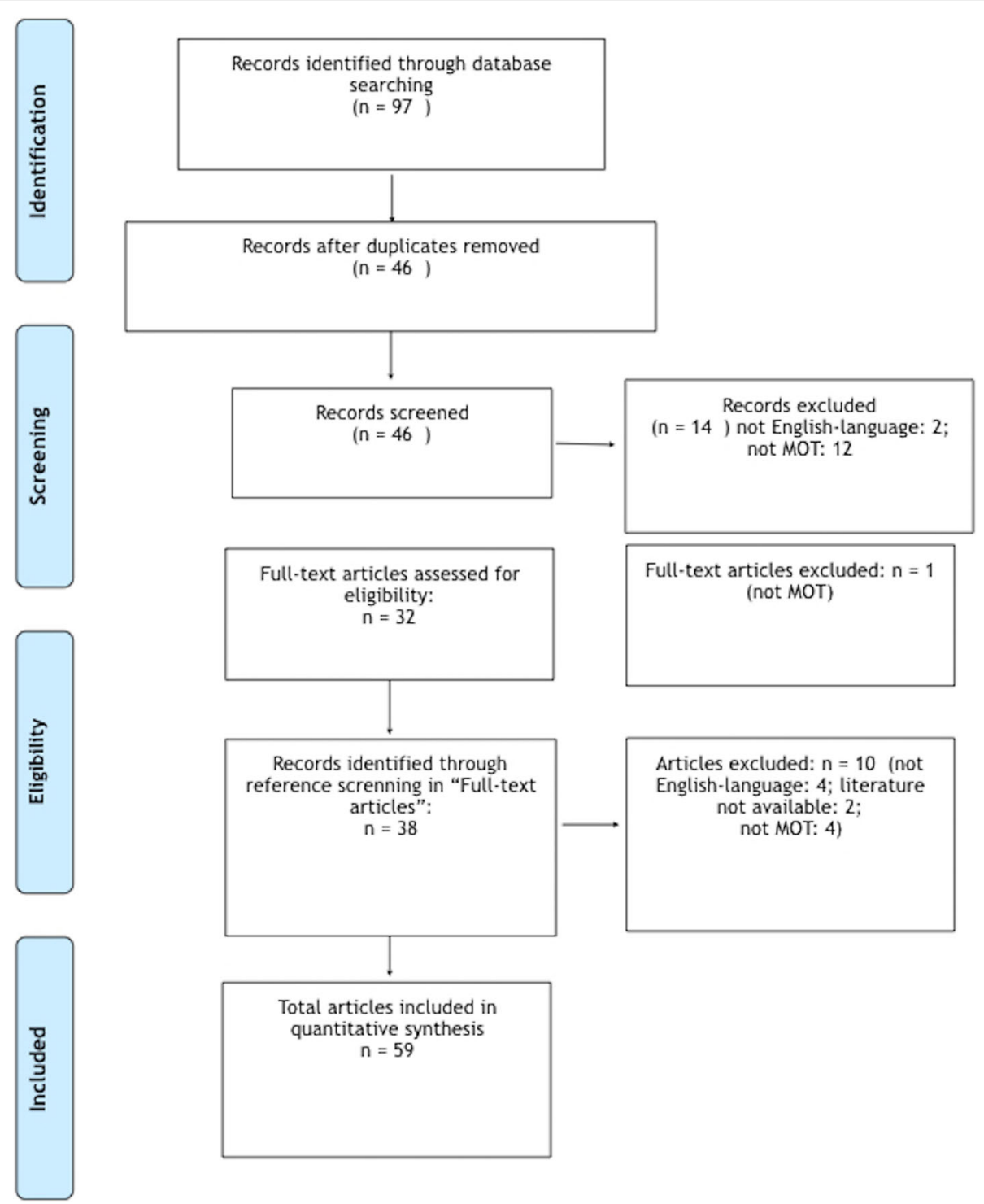

Fig. 1 Data analyses of recorded literature for MOT of the masticatory muscles according to PRISMA-Guidelines

\section{Treatment}

The most frequent described treatment for MOT was surgical excision $(n=23)$ followed by surgery and physical therapy $(n=22)$. In addition to surgery, interposition grafts and physical therapy were performed by five authors, interponate with silastic and physical therapy was reported in one case, while another author described interponate with silastic, physical therapy, and drug administration using diodronel. Didronel was administered in addition to surgery according to one report. The use of dermalgraft in combination with surgical excision was also reported in one case. The use of radiation and surgery in combination with physical therapy and drug administration with indomethacine and etidronate was furthermore published in one case. Exclusive physical therapy was done in four cases, while treatment in two reports was not indicated. Multiple surgeries were necessary in 9 patients. Two patients were not treated at all.

\section{Clinical outcome: No recurrence}

In 41 cases, no recurrence was reported after the first surgery. Nineteen out of these 41 cases were treated with a combination of surgery and physical therapy while 20 of 41 cases underwent exclusively surgery. One patient was treated with surgery in combination with physical and pharmacological therapy, while another patient was handled with surgery in combination with interponate and physical therapy. In contrast, recurrence took place in 11 cases whereas no treatment was performed or the outcome was not outlined in 11 cases. 


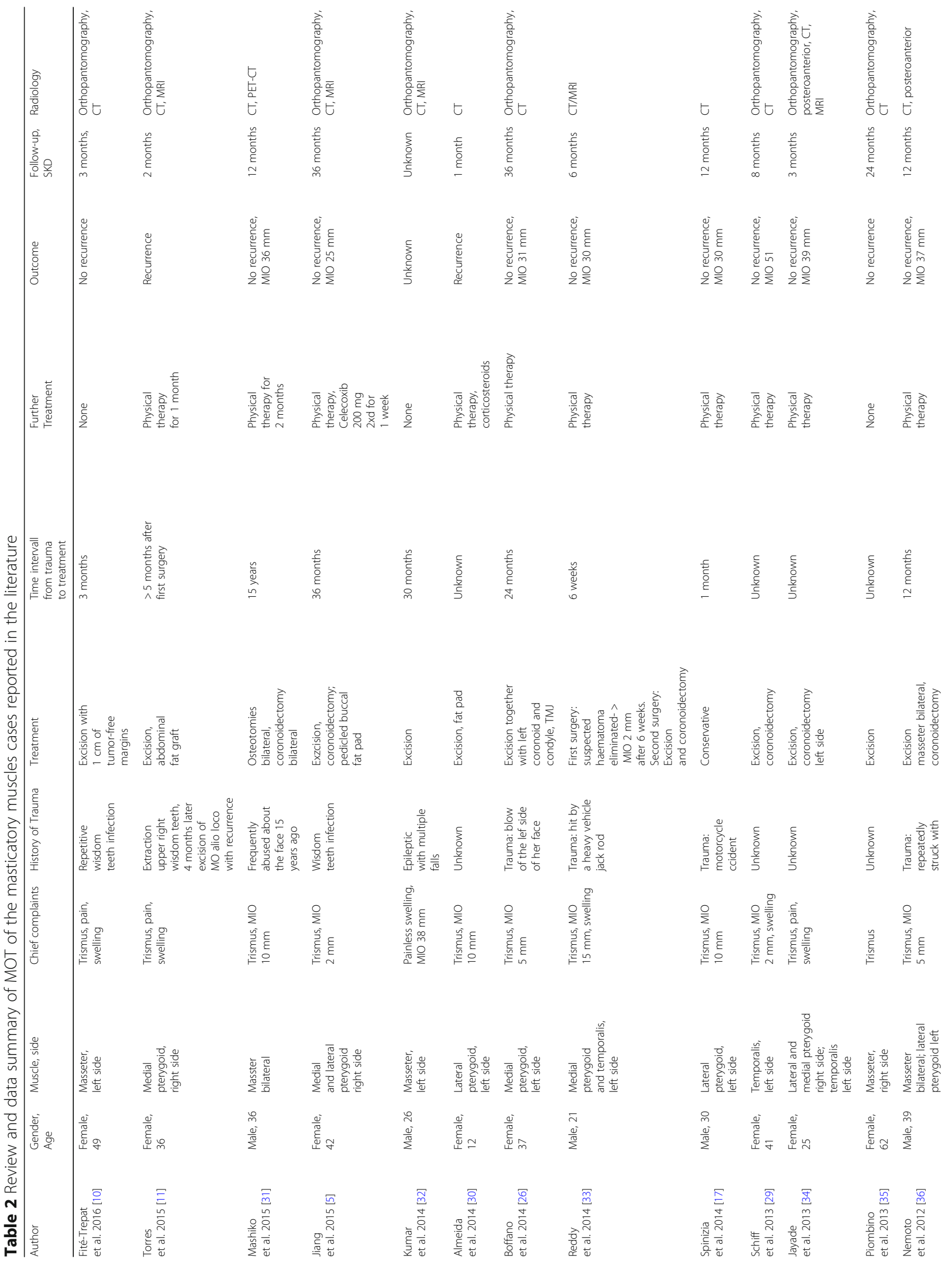




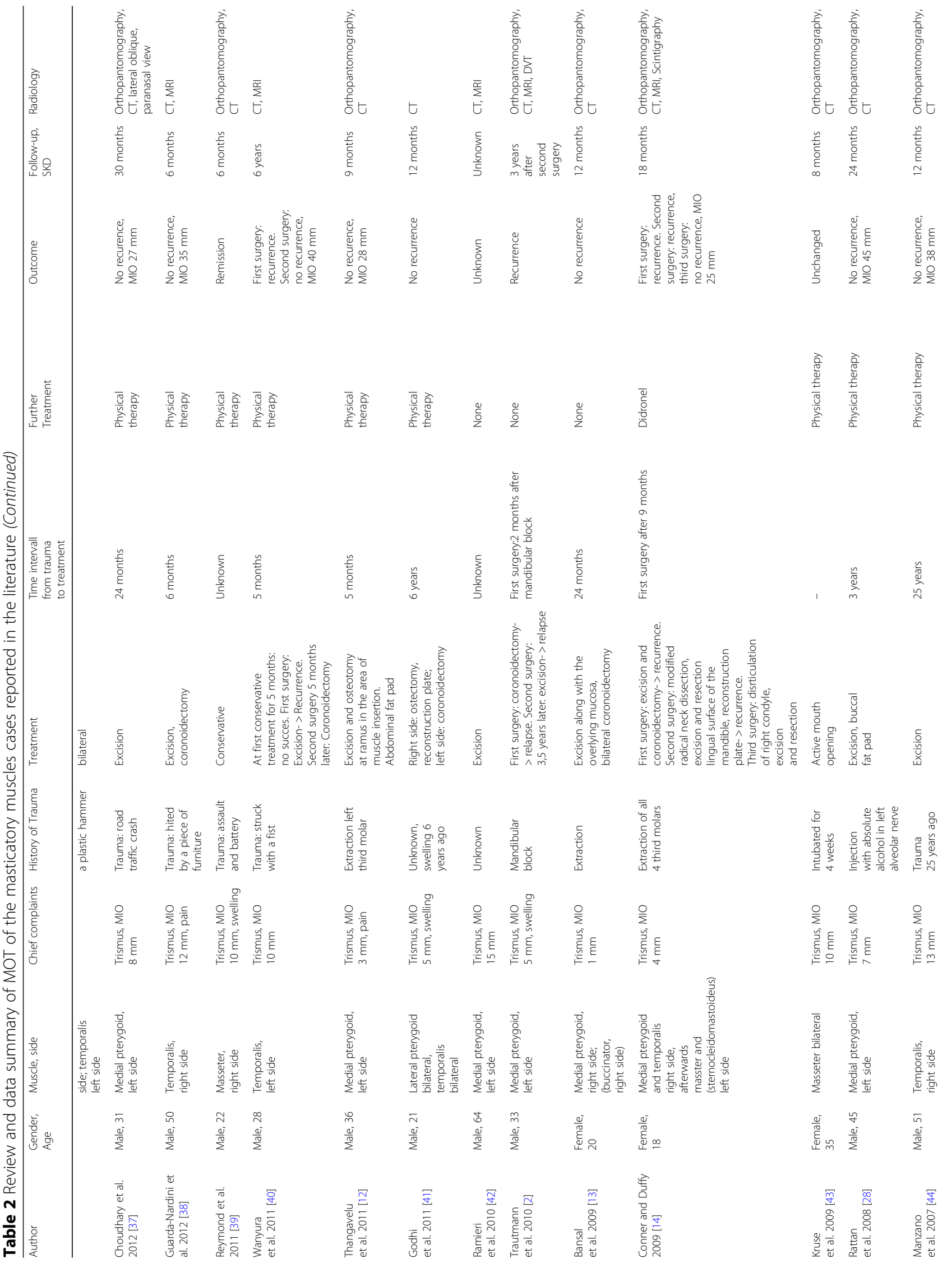




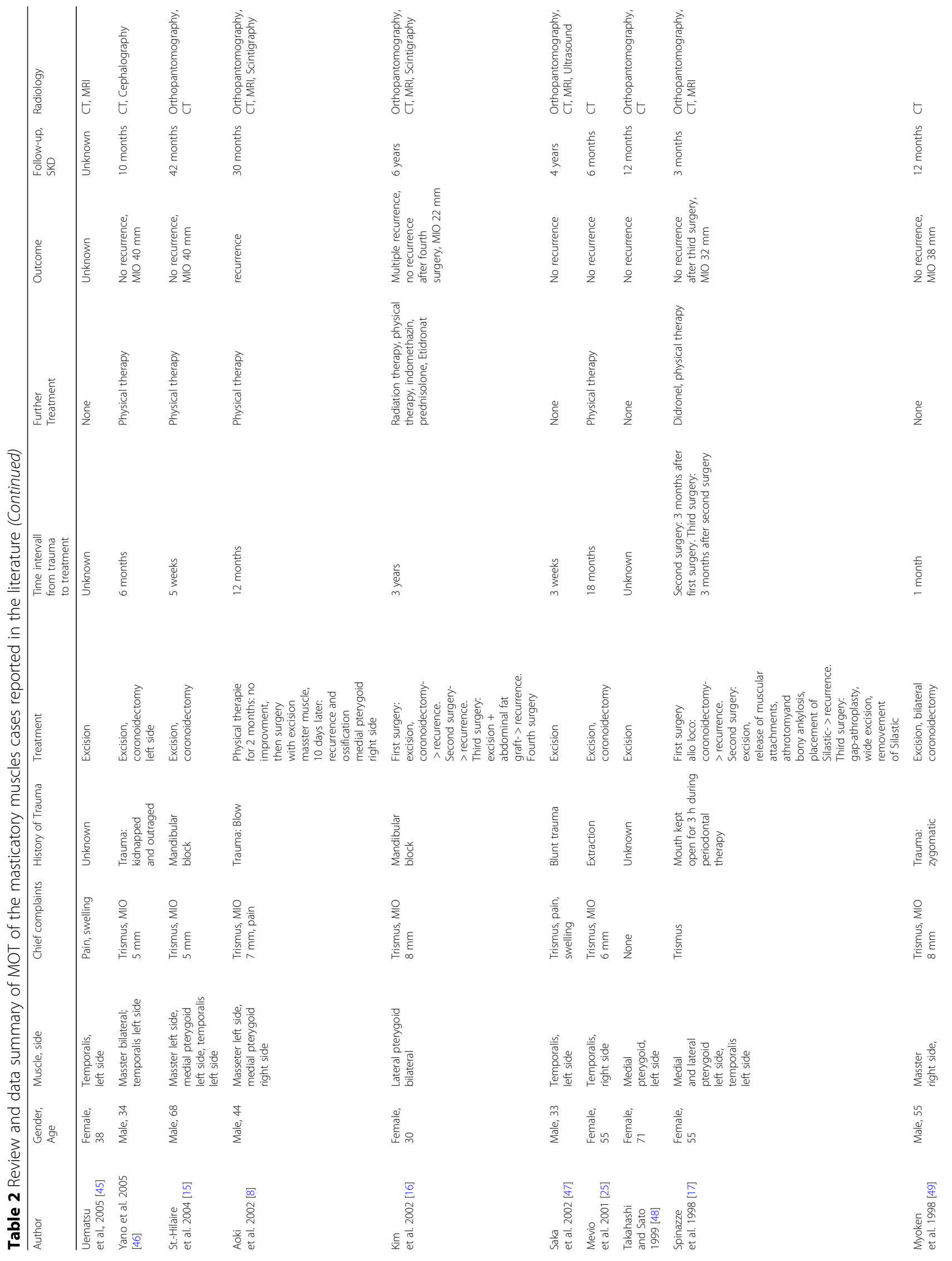




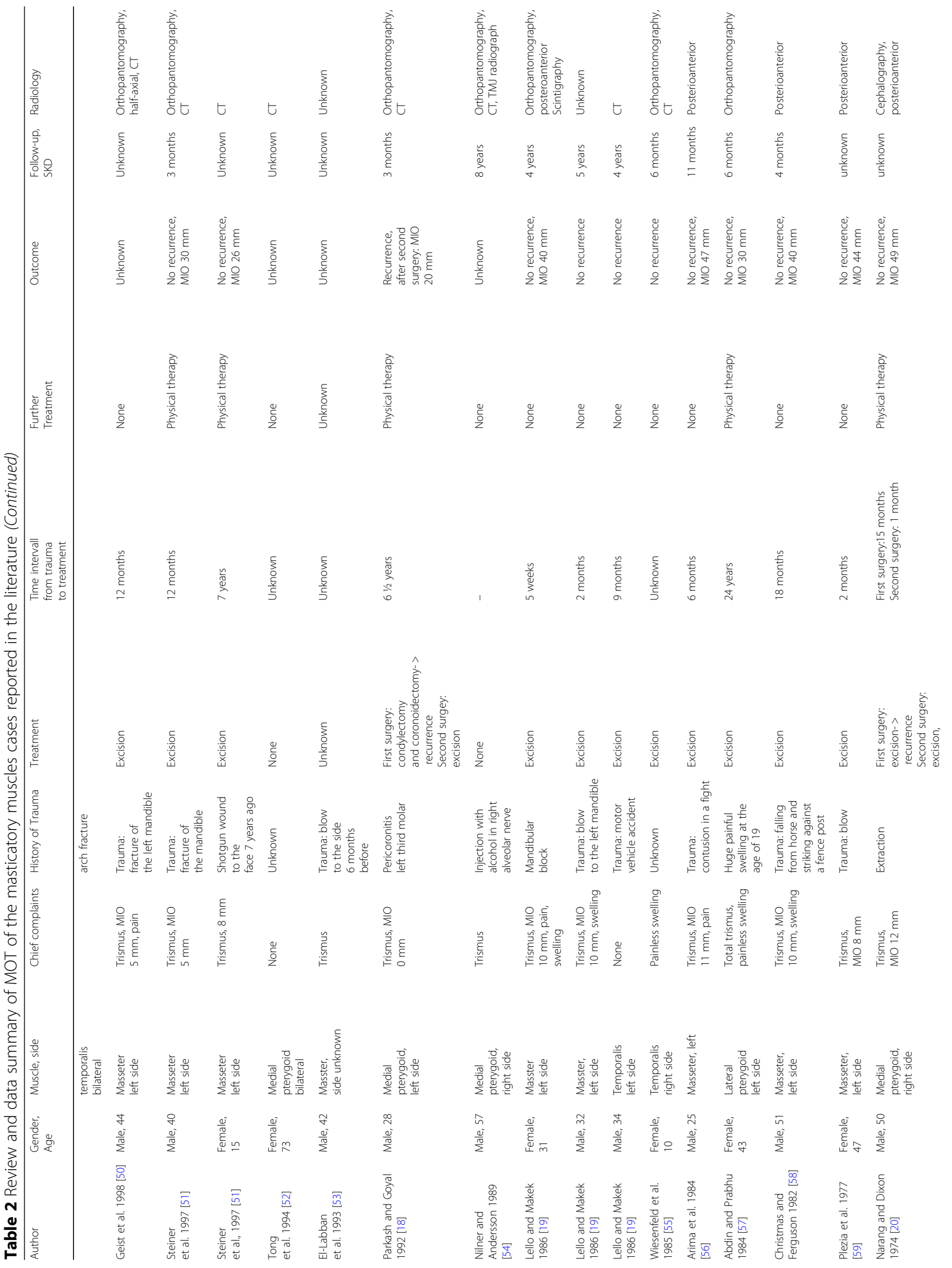




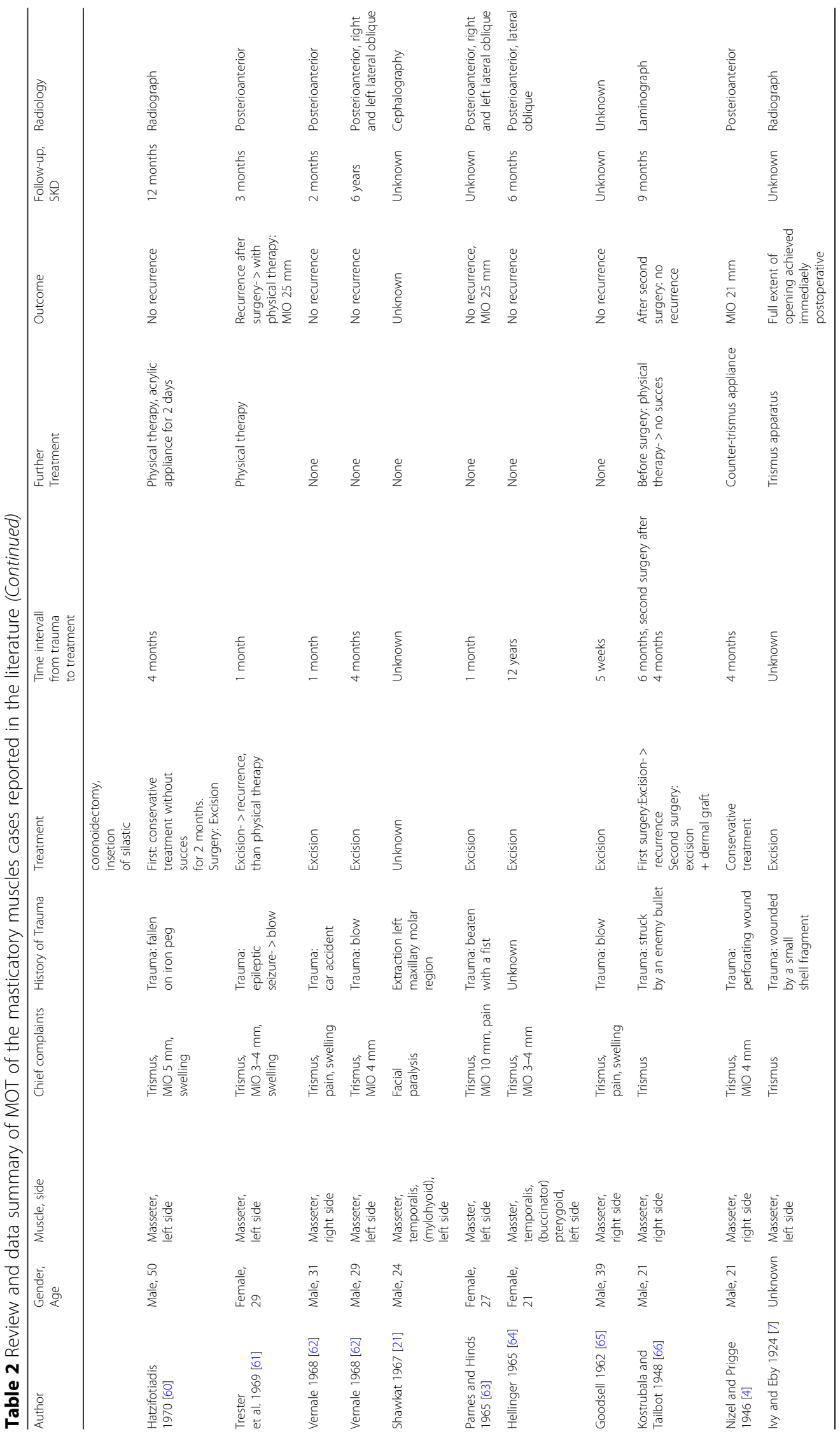




\section{Clinical outcome: Recurrence}

Recurrence was reported in a total of 11 cases. In 7 out of these cases multiple surgeries were performed which stopped any further recurrence. In four reports, unsuccessful treatment of MOT hampered recurrence analysis.

\section{Clinical outcome: Recurrence in correlation with time of treatment}

To evaluate the clinical outcome "recurrence" in correlation with time of treatment, two groups were defined. In the first group, surgery was performed less than 6 months after trauma $(n=21)$. In this group five cases with recurrence were stated. In the second group, the interval from trauma to treatment was longer than 6 months $(n=27)$. In that herein also five cases with clinical recurrence occurred. In one case undergoing recurrence no interval from trauma to treatment was indicated. In a total of 13 reports, the interval from trauma to treatment was not noted and in two cases no treatment was initiated.

\section{Clinical outcome: Recurrence in correlation with the type of treatment}

Recurrence after the first treatment was found in 3 cases in which only surgery took place. Surgery in combination with physical therapy led to 3 cases of recurrence. Surgery in combination with fat pad and physical therapy led to recurrence in two reports, while recurrence also occurred to a patient who was treated with surgery in combination with diodronel. Recurrence was also reported during treatment with surgery in combination with radiation, indomethacine, diodronel, and physical therapy, as well as surgery with silastic interponate, diodronel, and physical therapy.

\section{Clinical outcome: Maximal incisal opening (MIO) development}

In the group of successful treated patients, 20 authors reported about the development of MIO before and after therapy. MIO ranged from 15 to $49 \mathrm{~mm}$ in length with a mean of $29.6 \mathrm{~mm}$. Only physical therapy $(n=1)$ yielded a $20 \mathrm{~mm}$ long MIO. Surgery in combination with fat pad $(n=3)$ resulted in a MIO of $28.6 \mathrm{~mm}$ length (range: $23 \mathrm{~mm}-38 \mathrm{~mm}$ ), while the MIO of patients with surgery in combination with physical therapy $(n=12)$ exhibited a MIO of $27.2 \mathrm{~mm}$ length (range: $15 \mathrm{~mm}-49 \mathrm{~mm}$ ). Surgery alone $(n=4)$ yielded a MIO of $31.3 \mathrm{~mm}$ length (range: $30 \mathrm{~mm}-35 \mathrm{~mm}$ ).

\section{Risk of bias within studies}

In general, the risk of bias was considered low, since most part of the case reports were described in accordance to the check-list. Only 2 studies showed a percentage of positive response lower than 60\% (Supplement 1).

\section{Clinical documentation system screening}

After searching the clinical documentation system of the University Hospital Münster only one self-generated entry for MOT could be recovered.

\section{Clinical case reported by the authors}

A 28 year-old male was referred to our Clinic of Cranio-Maxillofacial Surgery with trismus in March 2016. The patient was not able to open or to close his mouth and, moreover, he was unable to protrude or to produce a lateral excursion. So he possessed an interincisal mouth opening of $5 \mathrm{~mm}$. The patient indicated that he underwent a filling therapy on the right mandible molar by his dentist 7 months ago. As according therapy a right mandibular nerve block was performed. Four weeks later the patient developed trismus. His dentist described oral antibiosis and physical examination. However, no clinical improvement was observed. Therefore, the patient was referred to a Clinic of Cranio-Maxillofacial Surgery where the diagnosis of pericoronitis of the lower right third molar was stated. Extraction of the right upper and lower third molar and a forced mouth-opening was performed under general anesthesia. Subsequently, the trismus disappeared but reappeared 2 weeks later. Because of this relapse, coronoidectomy was performed on the right side. Consequently, the trismus disappeared, but a relapse reoccurred a few weeks later. A multislice computer tomography (CT) of the head was performed and the CT revealed a calcification of the right medial pterygoid muscle (Fig. 2). Due to the given diagnosis of MOT of the right medial pterygoid, the patient was finally referred to the Clinic of Cranio-Maxillofacial Surgery at the University of Münster. For excluding MOP, we referred the patient to the department of human genetics. Indeed, MOP could be excluded and also all laboratory test results ranged within normal limits, including the resulting values for calcium, phosphate, alkaline phosphatase and parathyroid hormone measurements. Thus, we decided to perform renewed surgery 6 months after the last surgical intervention. Pre-operative radiation was performed with 6 Gy as single-dose radiation. Surgical excision of the ossified right medial pterygoid muscle was performed through combined intra- and extraoral access under general anesthesia. During this intervention, solid bone mass could be excised (Fig. 3). Histopathological analysis confirmed the diagnosis of MOT (Fig. 4). Physical therapy was started 2 days after surgery and 1 week after surgical intervention the patient could be released. Post-operative long-term application of 


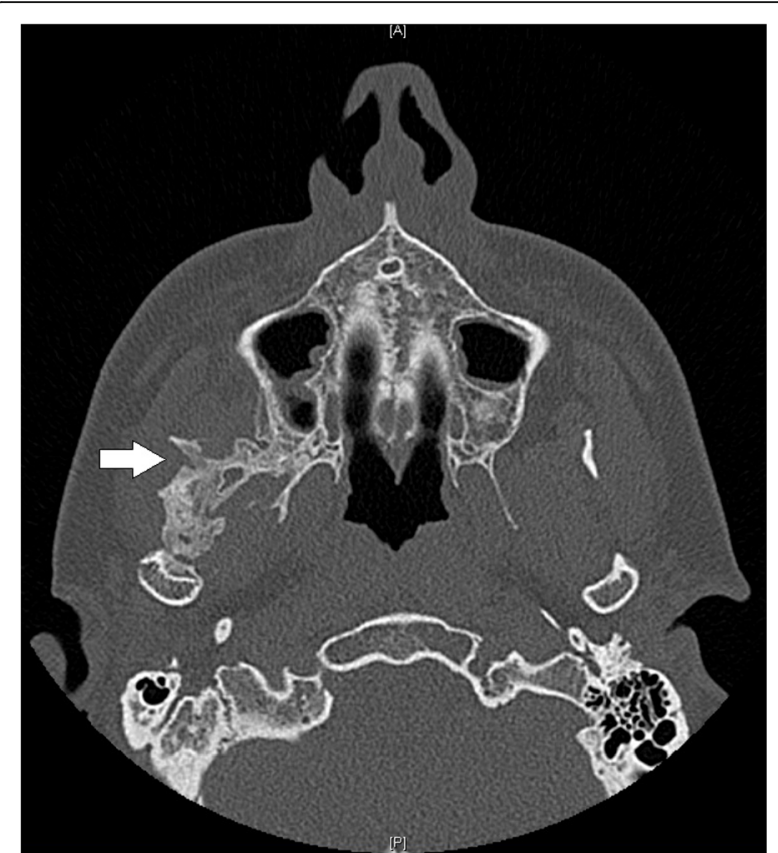

Fig. 2 Cone beam scan showing calcification of the right medial pterygoid

ibuprofen $400 \mathrm{mg}$ was performed for 2 weeks. At this time point, the MIO reached $23 \mathrm{~mm}$ in length. The patient was instructed to perform intensive physical therapy with an functional orthodontic gadget, the so-called "Jeckel-spreader", for exercising mouth opening. This device serves for mobilisation of the masticatory muscles. Two weeks later, the MIO still yielded $25 \mathrm{~mm}$ in length. Thereafter, the patient stopped physical therapy using the "Jeckel-spreader" against our recommendation. Consequently, the MIO decreased to $10 \mathrm{~mm}$ in length. Thus, we advised the patient strongly to restart physical therapy but he declined. Digital volume tomography (DVT) was performed which revealed renewed calcification (Fig. 5). Six months after surgery, MIO exhibited a

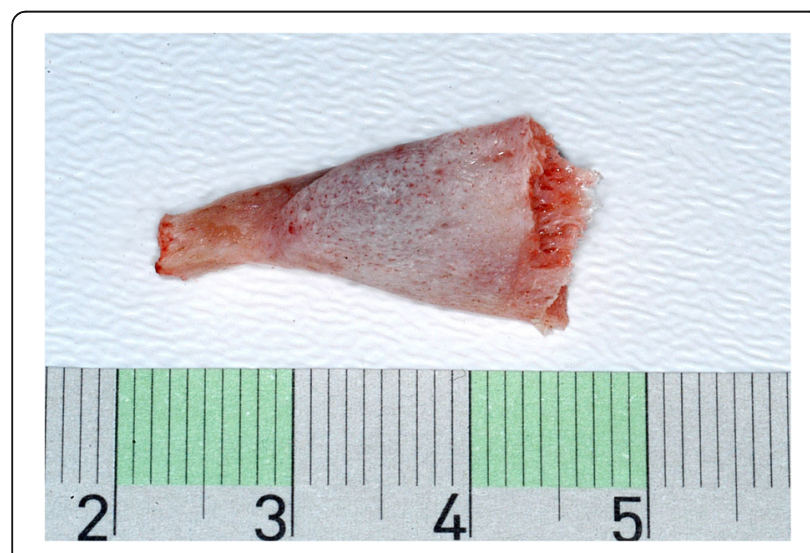

Fig. 3 Piece of the excised solid bone mass

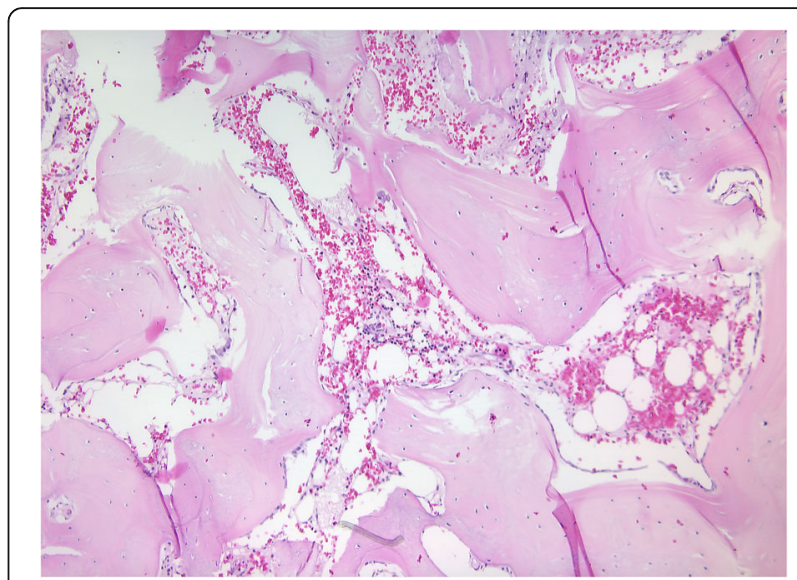

Fig. 4 Microscopic image of lesion demonstrating sclerotic, solid and cancellous bone with fatty bone marrow. (HE, magnification: 10-fold)

length of about $8 \mathrm{~mm}$. This enabled the patient to eat, to perform and to do a small lateral excursion.

We have derived a decision tree for diagnosis and treatement of MOT (Fig. 6).

Discussion The pathogenesis of MOT has not been finally clarified. In 1924, Carey [24] already listed four major theories for the development of MOT: 1) Displacement of bony fragments into soft tissue and hematoma with subsequent proliferation; 2) detachment of periosteal fragments into surrounding tissue with proliferation of osteoprogenitor cells; 3) migration of subperiostal osteoprogenitor cells into surrounding soft tissue through periosteal perforations induced by

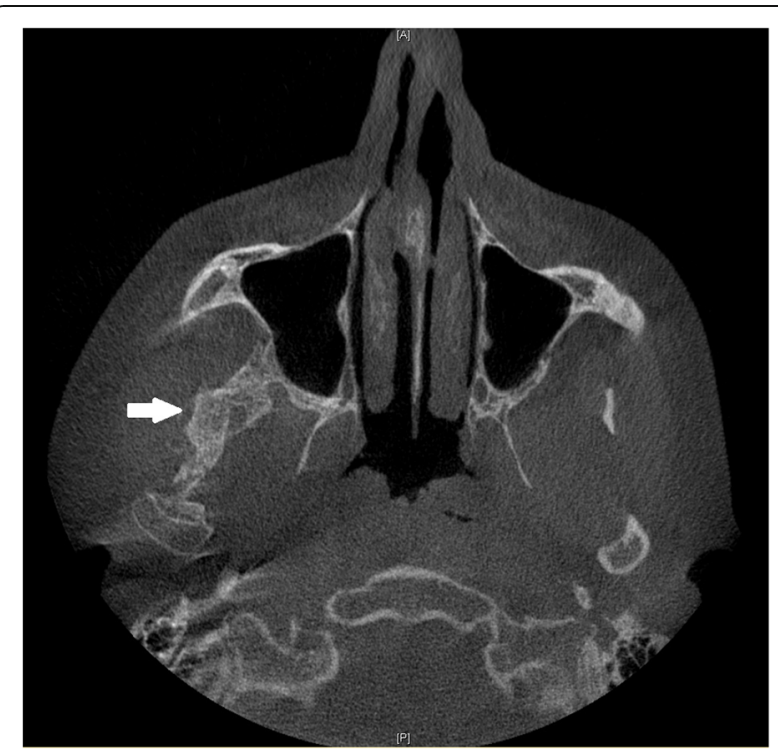

Fig. 5 Digital volume tomography showing recurrence of calcification 


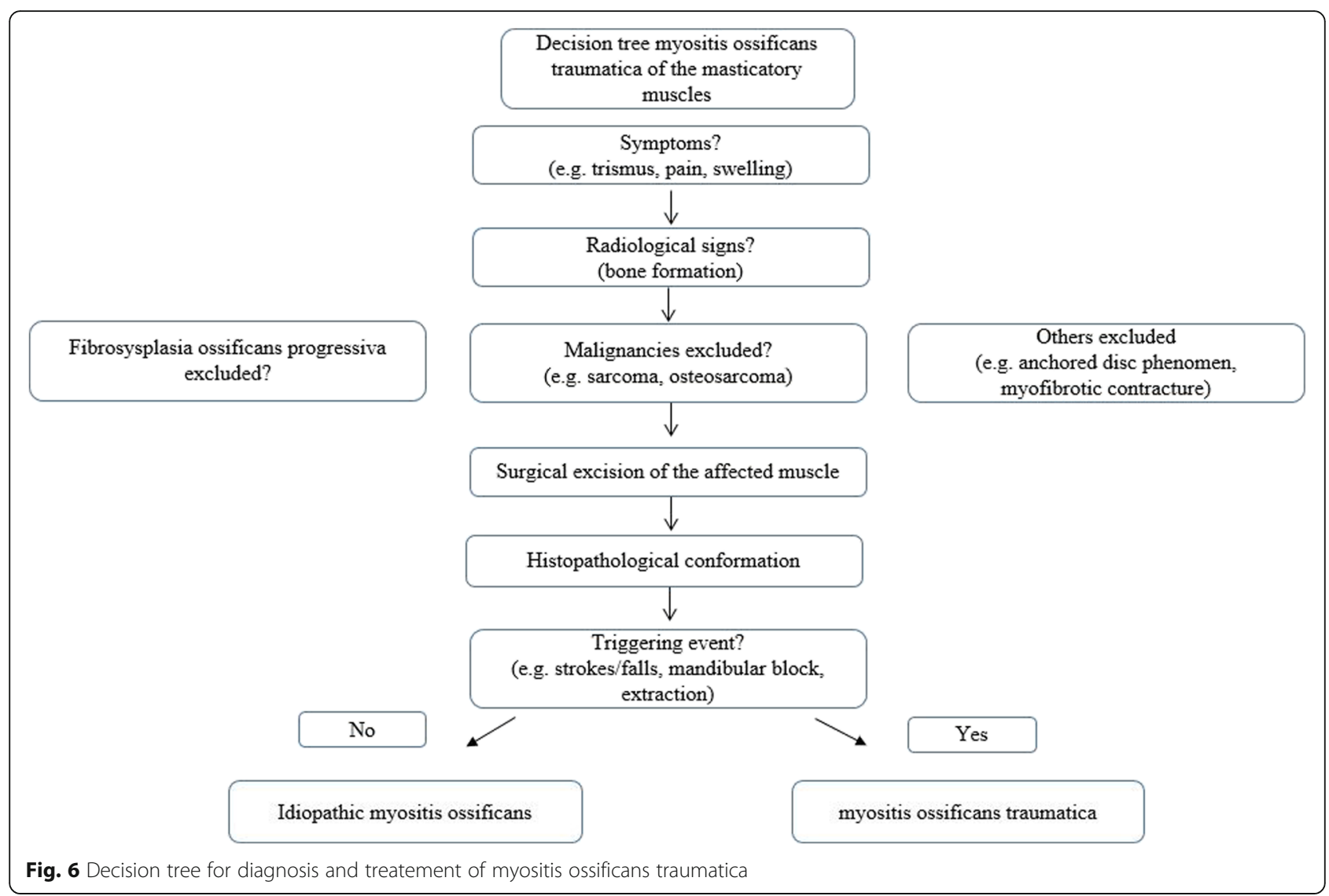

trauma; 4) differentiation of extraosseous cells exposed to bone morphogenic proteins. The results of the present study confirm the assumption,that multiple processes lead to the development of MOT. If a triggering event is present at all, its nature seems to be too heterogenous from case to case to support the theory of a single initiating cause. In 12 of the cases summarized here, no specific triggering traumatic event was identified (idiopathic myositis ossificans). Nevertheless, it seems that minor traumatic lesions unnoticed by these patients could be a possible cause. According to Torres [11] the intensity of the trauma may not be related to the occurrence of MOT. This statement could explain why no cases of MOT occurring in individuals that pursue the sport of boxing have been reported in the literature so far. These cases would be expected because of regularly occurring blows to the face and masticatory muscles (especially the masseter and temporal muscles) of boxers. On the other hand, a relation between dental surgery and the onset of MOT seems obvious. There are 7 case reports of MOT with previous tooth extraction $[11-14,20,21,25]$ though it is not possible to fully differentiate whether the extraction or the dental anesthesia in the context with the extraction represents the triggering event. The latter as a cause of MOT was reported in four cases $[2,15,16,19]$. Mandibular block as reported by Trautmann [2] as well as in our reported case, could be a more possible triggering factor for MOT. Therefore local anesthesia cannot be excluded as a cause of MOT occurring after periodontal treatment, either [17]. Furthermore, three cases of MOT following repetitive wisdom tooth infection have been published $[5,10,18]$. This would represent an additional indication requiring surgical removal of wisdom teeth if normal placement in the row of teeth is not expected.

Trismus is the most frequently observed symptom of MOT in the masticatory muscles which was also presented in our case. In this respect, MOT should be considered in the differential diagnosis in case of persisting trismus without a clinically manifesting cause. In such cases, radiographic findings are being expected only 36 weeks after the appearance of clinical symptoms [2].

So far, male patients have been considered as the main group at risk of developing MOT of the masticatory muscles with a male/female ratio of 2.4/1 [26]. However, our data analysis demonstrated a gender-specific difference to a lesser extent with a male/female ratio of approximately $1.5 / 1$. Since however MOT has been frequently related to traumas (e. g. fracture, blow) a possible explanation could be: males might have experienced traumas more often than females and thus also suffer more often from MOT. Of particular interest is 
the view at the cases of MOT occurring after dental treatment where more women $(n=9)$ were concerned than men $(n=6)$. This means prevalence for female patients of MOT of the masticatory musculature in context of dental treatment with a $1.5 / 1$ ratio.

In most cases of MOT of the masticatory muscles the masseter muscle is the most affected one [10]. However, this is not true for those cases of MOT occurring after dental treatment. Of these cases $(n=10), 66 \%$ involved the medial pterygoid muscle. Given the potential risk of damaging this muscle in the context of a mandibular nerve block, local dental anesthesia seems to be the cause of MOT here, as potentially in our case. Whether the patient has to be informed about this extremely rare complication remains questionable in view of the large numbers of local dental anesthesia administered daily. On the other hand the consequences represent a severe impairment for the patient. Nevertheless, MOT should be considered in the differential diagnosis in cases of therapy-resistant trismus developing in the weeks after local anesthesia.

Generally, excision of the affected muscle is recommended as treatment of choice [10]. However, there are different opinions about the time when the excision has to be done and about possible additional measures, such as the use of interpositional materials, treatment with drugs, or physical therapy. Some authors recommended $[12,14,27]$ that the excision as well as the use of interpositional material should be performed after complete maturation, about 6 to 12 months after initial symptoms. In contrast, other authors prefered excision at an early stage [11]. There were five relapses, both, in the group of early excision (treatment less than six months after first symptoms), and in the group of excision at a later stage (treatment more than six months after first symptoms). However, the group with intervention at a later time point included 27 cases that was somewhat bigger than the early-intervention group $(n=21)$. Nonetheless, it is not possible to make any clear recommendation for the ideal time point of surgical intervention based on these data.

While some authors suggested aggressive physical therapy after surgical excision [17], others advised against this procedure [14]. They feared that physical therapy stimulates bone formation with the consequence of exacerbation of MOT. Of the 22 reported cases undergoing excision combined with physical therapy, 3 cases relapsed. In the group of 23 patients who only underwent excision without physical therapy there were also 3 relapses. In consequence, no difference in the rate of recurrence was found depending on physical therapy.

In addition to excision, - with or without physical therapy, the use of interpositional materials $[12,16,17$,
$20,28]$ or pharmaceuticals, such as etidronate or ibuprofen [29] have been proposed. Often, these additional measures were applied in clinical cases with multiple recurrences $[11,14,16,17,30]$ so that the benefit of additional treatment cannot be assessed conclusively.

The major limitation of this review is the rarity of the evaluated condition, resulting in a lack of research sources which could offer reliable evidence-based information. With this regard, all studies selected for this review were case reports, which hampered a deeper analysis of risk of bias of each study. Nonetheless, the present study aimed to offer a guide decision for the management and diagnosis of MOT. Additionally, the case reported described the authors clinical experience regarding this condition and shows a treatment option for patients with MOT.

\section{Conclusions}

Dental procedures, such as local anesthesia or extractions, may cause MOT of the masticatory musculature. Women have a higher risk of developing MOT with respect to dental treatment. The most important treatment option for MOT is surgical excision and subsequent physical therapy can have beneficial effects. A benefit of interpositional materials and drugs as therapy of MOT of the masticatory muscles has not yet been proven. MOP has to be excluded.

\section{Additional file}

Additional file 1. Quality assessment of the included literature. (DOC $139 \mathrm{~kb})$

\section{Abbreviations}

CT: Computer tomography; DVT: Digital volume tomography; MIO: Maximal incisal opening; MOP: Myositis ossificans progressiva; MOT: Myositis ossificans traumatica

\section{Acknowledgements}

We acknowledge support by Open Access Publication Fund of University of Muenster.

\section{Funding}

This research did not receive any specific grant from funding agencies in the public, commercial, or not-for-profit sectors.

\section{Availability of data and materials}

The datasets supporting the conclusions of this article are available at the Department of Cranio-Maxillofacial Surgery, University Hospital Münster Germany.

\section{Authors' contributions}

$\mathrm{MH}, \mathrm{LH}$ reviewed the literature. JK, RW, LB and LFF helped in the interpretation of data. $\mathrm{MH}$ analysed the dabase of the clinic. $\mathrm{MH}, \mathrm{LH}, \mathrm{JK}, \mathrm{RW}$, LB and LFF participated in design, and drafting of the manuscript. All authors read and approved the final manuscript.

Ethics approval and consent to participate

The ethical approval for this study was obtained from the ethical review committee (Ref. no. 2017-052-f-N), Ethikkommission der Ärztekammer 
Westfalen-Lippe und der Westfälischen Wilhelms-Universität, Münster, Germany.Written informed consent was obtained from the patient.

\section{Consent for publication}

Written informed consent was obtained from the patient for publication of the case report and any accompanying images. A copy of the written consent is available for review by the Editor-in-Chief of this journal.

\section{Competing interests}

The authors declare that they have no competing interests.

\section{Publisher's Note}

Springer Nature remains neutral with regard to jurisdictional claims in published maps and institutional affiliations.

\section{Author details}

'Department of Cranio-Maxillofacial Surgery, Research Unit Rare Diseases with Orofacial Manifestations (RDOM), University Hospital Münster, Albert-Schweitzer-Campus 1, Gebäude W 30, D-48149 Münster, Germany. 2Department of Orthodontics, Faculty of Health, School of Dentistry, Witten/ Herdecke University, Alfred-Herrhausen-Strasse 44, 58455 Witten, Germany. ${ }^{3}$ Department of Cranio-Maxillofacial Surgery, AG VABOS, University Hospital Münster, Albert-Schweitzer-Campus 1, Gebäude W 30, D-48149 Münster, Germany. ${ }^{4}$ Department of Oral and Maxillofacial Surgery, Central German Armed Forces Hospital, Rübenacher Strasse 170, 56072 Koblenz, Germany.

\section{Received: 9 April 2018 Accepted: 15 October 2018}

Published online: 29 October 2018

\section{References}

1. Kaplan FS, Seemann P, Haupt J, Xu M, Lounev VY, Mullins M, Shore EM. Investigations of activated ACVR1/ALK2, a bone morphogenetic protein type I receptor, that causes fibrodysplasia ossificans progressiva. Methods Enzymol. 2010;484:357-73.

2. Trautmann F, Pd M, Fernandes TL, Gondak RO, Castilho JC, Filho EM Myositis ossificans traumatica of the medial pterygoid muscle: a case report J Oral Sci. 2010 Sep;52(3):485-9.

3. Wiggins RL, Thurber D, Abramovitch K, Bouquot J, Vigneswaran N. Myositis ossificans circumscripta of the buccinator muscle: first report of a rare complication of mandibular third molar extraction. J Oral Maxillofac Surg. 2008 Sep;66(9):1959-63.

4. Nizel AE, Prigge EK. Trismus due to myositis ossificans traumatica; report of a case. J Oral Surg. 1946;4:93-101

5. Jiang Q, Chen MJ, Yang C, Qiu YT, Tian Z, Zhang ZY, Qiu WL. Post-infectious myositis ossificans in medial, lateral pterygoid muscles: a case report and review of the literature. Oncol Lett. 2015;9(2):920-6.

6. Jayade B, Adirajaiah S, Vadera H, Kundalaswamy G, Sattur AP, Kalkur C. Myositis ossificans in medial, lateral pterygoid, and contralateral temporalis muscles: a rare case report. Oral Surg Oral Med Oral Pathol Oral Radiol. 2013;116(4):261-6.

7. Ivy and Eby: The medical Dept. of the United States Army, U.S government printing office, 1924, Vol. II, Sec 2; P. 457.

8. Aoki T, Naito H, Ota Y, Shiiki K. Myositis ossificans traumatica of the masticatory muscles: review of the literature and report of a case. J Oral Maxillofac Surg. 2002;60(9):1083-8.

9. Ackermann LV. Extra-osseous localized non-neoplastic bone and cartilage formation (so-called myositis ossificans): clinical and pathological confusion with malignant neoplasms. J Bone Joint Surg Am 1958;40-A(2):279-298.

10. Fité-Trepat L, Martos-Fernández M, Alberola-Ferranti M, Romanini-Montecino C, Saez-Barba M, Bescós-Atín C. Myositis ossificans of the masseter muscle: a rare location. Report of a case and review of literature. J Clin Exp Dent. 2016;8(2):210-3.

11. Torres AM, Nardis AC, da Silva RA, Savioli C. Myositis ossificans traumatica of the medial pterygoid muscle following a third molar extraction. Int J Oral Maxillofac Surg. 2015;44(4):488-90.

12. Thangavelu A, Vaidhyanathan A, Narendar R. Myositis ossificans traumatica of the medial pterygoid. Int J Oral Maxillofac Surg. 2011;40(5):545-9.

13. Bansal V, Kumar S, Mowar A. Unusual causes of trismus: a report of two cases. J Maxillofac Oral Surg. 2009;8(4):377-80.
14. Conner GA, Duffy M. Myositis ossificans: a case report of multiple recurrences following third molar extractions and review of the literature. J Oral Maxillofac Surg. 2009;67(4):920-6.

15. St -Hilaire H, Weber WD, Ramer M, Lumerman H. Clinicopathologic conference: trismus following dental treatment. Oral Surg Oral Med Oral Pathol Oral Radiol Endod. 2004;98(3):261-6.

16. Kim DD, Lazow SK, Har-El G, Berger JR. Myositis ossificans traumatica of masticatory musculature: a case report and literature review. J Oral Maxillofac Surg. 2002 Sep;60(9):1072-6.

17. Spinazze RP, Heffez LB, Bays RA. Chronic, progressive limitation of mouth opening. J Oral Maxillofac Surg. 1998;56(10):1178-86.

18. Parkash H, Goyal M. Myositis ossificans of medial pterygoid muscle. A cause for temporomandibular joint ankylosis. Oral Surg Oral Med Oral Pathol. 1992;73(1):27-8

19. Lello GE, Makek M. Traumatic myositis ossificans in masticatory muscles. J Maxillofac Surg. 1986;14(4):231-7

20. Narang R, Dixon RA Jr. Myositis ossificans: medial pterygoid muscle-a case report. Br J Oral Surg. 1974;12(2):229-34.

21. Shawkat AH, Myositis ossificans. Report of a case. Oral Surg Oral Med Oral Pathol. 1967;23(6):751-4.

22. Moher D, Liberati A, Tetzlaff J, Altmann DG, The PRISMA Group. Preffered Reporting Items for Systematic Reviews and Meta Analyses: The PRISMA Statement. PLoS Med. 2009:6(7):e1000097.

23. Moola S, Munn Z, Tufanaru C, Aromataris E, Sears K, Sfetcu R, Currie M, Qureshi R, Mattis P, Lisy K, P-F M. Chapter 7: Systematic reviews of etiology and risk: The Joanna Briggs Institute; 2017. https://reviewersmanual. joannabriggs.org.

24. Carey EJ. Multiple bilateral parosteal bone and callus formations of the femur and left innominate bone. Arch Surg. 1924:8:592

25. Mevio E, Rizzi L, Bernasconi G. Myositis ossificans traumatica of the temporal muscle: a case report. Auris Nasus Larynx. 2001:28(4):345-7.

26. Boffano P, Zavattero E, Bosco G, Berrone S. Myositis ossificans of the left medial pterygoid muscle: case report and review of the literature of myositis ossificans of masticatory muscles. Craniomaxillofac Trauma Reconstr. 2014;7(1):43-50.

27. Ferlito A, Barion U, Nicolai P. Myositis ossificans of the head and neck. Review of the literature and report of a case. Arch Otorhinolaryngol. 1983; 237(2):103-13.

28. Rattan V, Rai S, Vaiphei K. Use of buccal pad of fat to prevent heterotopic bone formation after excision of myositis ossificans of medial pterygoid muscle. J Oral Maxillofac Surg. 2008 Jul;66(7):1518-22.

29. Schiff MJ, Meara DJ. Myositis ossificans of the temporalis muscle: case report and review of the literature. J Oral Maxillofac Surg. 2013;71(11):1893-8.

30. Almeida LE, Doetzer A, Camejo F, Bosio J. Operative management of idiophatic myositis ossificans of lateral pterygoid muscle. Int J Surg Case Rep. 2014:5(11):796-9.

31. Mashiko T, Akizuki T, Watanabe Y, Sasaki R, Yokoyama M, Yoshimura K, Mineda K. Clinicopathologic assessment of myositis Ossificans Circumscripta of the masseter muscles. J Craniofac Surg. 2015 Sep;26(6):2025-6.

32. Kumar N, Austin RD, Mathew P, Sakthivel S, Vijayalakshmi L. Traumatic myositis ossificans of the masseter muscle: a case report with conventional and advanced imaging features. Gen Dent. 2014;62(5):75-7.

33. Reddy SP, Prakash AP, Keerthi M, Rao BJ. Myositis ossificans traumatica of temporalis and medial pterygoid muscle. J Oral Maxillofac Pathol. 2014; 18(2):271-5.

34. Jayade B, Adirajaiah S, Vadera H, Kundalaswamy G, Sattur AP, Kalkur C. Myositis ossificans in medial, lateral pterygoid, and contralateral temporalis muscles: a rare case report. Oral Surg Oral Med Oral Pathol Oral Radiol. 2013;116(4):e261-6.

35. Piombino P, Dell'Aversana Orabona G, Abbate V, Fini G, Liberatore GM, Mici E, Belli E. Circumscribed myositis ossificans of the masseter muscle: report of a case G Chir 2013:34(9-10):271-4.

36. Nemoto H, Sumiya N, Ito $Y$, Kimura N, Akizuki A, Maruyama N. Myositis ossificans traumatica of the masticatory muscles. J Craniofac Surg. 2012; 23(5):e514-6.

37. Choudhary AK, Sahoo NK, Chattopadhyay PK. Myositis ossificans traumatica of the medial pterygoid muscle: a case report. J Oral Maxillofacial Surg Med Pathol. 2012:24:241-4

38. Guarda-Nardini L, Piccotti F, Ferronato G, Manfredini D. Myositis ossificans traumatica of the temporalis muscle: a case report and diagnostic considerations. Oral Maxillofac Surg. 2012 Jun;16(2):221-5. 
39. Reymond J, Podsiadlo M, Zaniewicz R, Legowik T. Suspicion of posttraumatic myositis ossificans: diagnostic difficulties-case report. J Stoma. 2011;64(5-6):425-32.

40. Wanyura H, Stopa Z, Brzozowski F. Limited mouth opening caused by myositis ossificans traumatica of the temporal muscle. J Stoma. 2011;64(9):656-66.

41. Godhi SS, Singh A, Kukreja P, Singh V. Myositis ossificans circumscripta involving bilateral masticatory muscles. J Craniofac Surg. 2011;22(6):11-3.

42. Ramieri V, Bianca C, Arangio P, Cascone P. Myositis ossificans of the medial pterygoid muscle. J Craniofac Surg. 2010;21(4):1202-4.

43. Kruse AL, Dannemann C, Grätz KW. Bilateral myositis ossificans of the masseter muscle after chemoradiotherapy and critical illness neuropathy-report of a rare entity and review of literature. Head Neck Oncol. 2009;1:30.

44. Manzano D, Silván A, Saez J, Moreno JC. Myositis ossificans of the temporalis muscle. Case report. Med Oral Patol Oral Cir Bucal. 2007;12(4): 277-80.

45. Uematsu Y, Nishibayashi H, Fujita K, Matsumoto H, Itakura T. Myositis ossificans of the temporal muscle as a primary scalp tumor. Neurol Med Chir (Tokyo). 2005;45:56-8.

46. Yano $\mathrm{H}$, Yamamoto H, Hirata R, Hirano A. Post-traumatic severe trismus caused by impairment of the masticatory muscle. J Craniofac Surg. 2005; 16(2):277-80.

47. Saka B, Stropahl G, Gundlach KK. Traumatic myositis ossificans (ossifying pseudotumor) of temporal muscle. Int J Oral Maxillofac Surg. 2002;31(1):110-1.

48. Takahashi K, Sato K. Myositis ossificans traumatica of the medial pterygoid muscle. J Oral Maxillofac Surg. 1999;57(4):451-6.

49. Myoken Y, Sugata T, Tanaka S. Traumatic myositis ossificans of the temporal and masseter muscle. Br J Oral Maxillofac Surg. 1998;36(1):76.

50. Geist JR, Bhatti P, Plezia RA, Wesley RK. Fibrodysplasia ossificans circumscripta of the masseter muscle. Dentomaxillofac Radiol. 1998;27(3):182-5.

51. Steiner M, Gould AR, Kushner GM, Lutchka B, Flint R. Myositis ossificans traumatica of the masseter muscle: review of the literature and report of two additional cases. Oral Surg Oral Med Oral Pathol Oral Radiol Endod. 1997;84(6):703-7.

52. Tong KA, Christiansen EL, Heisler W, Hinshaw DB Jr, Hasso AN. Asymptomatic myositis ossificans of the medial pterygoid muscles: a case report. J Orofac Pain. 1994;8(2):223-6.

53. El-Labban NG, Hopper C, Barber P. Ultrastructural finding of vascular degeneration in myositis ossificans circumscripta (fibrodysplasia ossificans). J Oral Pathol Med. 1993;22(9):428-31.

54. Nilner M, Petersson A. Mandibular limitation due to enlarged pterygoid process and calcification of the medial pterygoid muscle. A case report. Cranio. 1989;7(3):230-4.

55. Wiesenfeld D, Evans FJ, Johnson N. Pseudomalignant osseous tumor of the temporalis muscle. J Oral Maxillofac Surg. 1985;43(10):786-9.

56. Arima R, Shiba R, Hayashi T. Traumatic myositis ossificans in the masseter muscle. J Oral Maxillofac Surg. 1984;42(8):521-6.

57. Abdin HA, Prabhu SR. Traumatic myositis ossificans of lateral pterygoid muscle. J Oral Med. 1984;39(1):54-6.

58. Christmas PI, Ferguson JW. Traumatic myositis ossificans. Br J Oral Surg. 1982:20(3):196-9.

59. Plezia RA, Mintz SM, Calligaro P. Myositis ossificans traumatica of the masseter muscle. Report of a case. Oral Surg Oral Med Oral Pathol. 1977; 44(3):351-7.

60. Hatzifotiadis D. Traumatic myositis ossificans: report of a case. Trans Int Conf Oral Surg. 1970:141-7.

61. Trester PH, Markovitch E, Zambito RF, Stratigos GT. Myositis ossificans, circumscripta and progressiva, with surgical correction of the masseter muscle: report of two cases. J Oral Surg. 1969;27(3):201-5.

62. Vernale CA. Traumatic myositis ossificans of the masseter muscle. Report of two cases. Oral Surg Oral Med Oral Pathol. 1968;26(1):8-17.

63. Parnes El, Hinds EC. Traumatic myositis ossificans of the masseter muscle: report of a case. J Oral Surg. 1965;23:245-50.

64. Hellinger MJ. Myositis ossificans of the muscles of the mastication. Oral Surg Oral Med Oral Pathol. 1965;19:581-7.

65. Goodsell JO. Traumatic myositis ossificans of the masseter muscle: review of the literature and report of a case. J Oral Surg Anesth Hosp Dent Serv. 1962;20:116-22.

66. Kosturbala JG, Talbot RJ. Myositis ossificans of the masseter muscle; a case report. Plast Reconstr Surg (1946). 1948;3(1):52-5.

\section{Ready to submit your research? Choose BMC and benefit from}

- fast, convenient online submission

- thorough peer review by experienced researchers in your field

- rapid publication on acceptance

- support for research data, including large and complex data types

- gold Open Access which fosters wider collaboration and increased citations

- maximum visibility for your research: over $100 \mathrm{M}$ website views per year

At BMC, research is always in progress.

Learn more biomedcentral.com/submissions 